\title{
Endomarketing based on Neuro-linguistic Programming
}

\author{
Ligia Bermudez ${ }^{\# 1}$, Raúl J. Martelo ${ }^{* 2}$, Piedad M. Montero ${ }^{* 3}$ \\ \# Industrial Engineer, Tus Pisos Enterprise Maracaibo, Zulia, Venezuela \\ ${ }^{1}$ ligia312@gmail.com \\ * Faculty of Engineering, University of Cartagena, Cartagena, Bolívar, Colombia. \\ 2 rmartelog1@unicartagena.edu.co \\ 3 pmargaritamontero@unicartagena.edu.co
}

\begin{abstract}
The objective of the present investigation was to analyze the Endomarketing based on Neurolinguistic Programming (NLP) present in the self-service hardware stores of the Maracaibo Municipality. The methodology used responds to the type of non-experimental, cross-sectional, descriptive research. As a result, it was obtained that the Endomarketing variable based on NLP is given an adequate management. The above is a consequence of an adequate level in the dimensions of Endomarketing factors, NLP metamodels and sensory perception systems. It also concludes, among other aspects, that internal factors, technical skills and seniority, are controlled and have a positive influence on the process. Finally, it is recommended to go to experts in the area of NLP so that through experiential workshops the representative systems of the advisors are identified and strategies are established for their proper use.
\end{abstract}

Keyword - Sensory perception systems, NLP, Endomarketing

\section{INTRODUCTION}

Neuro-linguistic programming (NLP) is a tool that allows us to improve interpersonal communication by explaining in a coherent way, how the human mind works and how it processes information into experience, using these experiences in a positive and very subjective way to achieve benefits personal, professional and in organizations [1]. For this reason, NLP is used in professional fields such as marketing, management and sports training. In marketing, for example, the market segments are composed of individuals who, although they have similarities among the traditional segmentation bases, also have different sensory modalities. Therefore, if consumers within a segment of the target market do not speak the same sensory language, marketers do not send their message to everyone in that segment [2].

Successful companies realize that the real competitive advantage lies in their people, so, NLP is emerging as an effective tool because it is recognized as one of the best available sources of knowledge about people's skills. This is significant, because employees are the most important asset of a company, and using NLP skills to maintain a good relationship with and with employees is crucial. Therefore, the acquisition of NLP skills would make them successful [3]. However, although NLP is not yet popular, given that it is still a relatively recent concept, people and businesses are increasingly aware of the concept and its tangible positive influence on business performance [4].

For example, in [5], the role of Neuro-linguistic Programming in the construction of the capacities of an organization is examined. Their results revealed that NLP gives managers and staff a significant improvement in efficiency to work, understand and motivate other people, both individually and in groups. Furthermore, it is revealed that an NLP-oriented manager is solid in all aspects, especially with the human factor, which is the vital element in this scenario. On the other hand, Endomarketing provides a perspective to attract and retain employees of continuous quality. The focus is on visualizing employees as customers (internal customer) and developing work packages for each employee segment [6].

However, complementing the Endomarketing with Neuro-linguistic programming, excellent results can be obtained and substantially improve the way the employee approaches his client, providing an excellent attention, because the quality of service has great importance for every company. Customers are even more critical every day and demand a quality service that meets their needs. Therefore, we must start by satisfying the needs of the internal customer of each organization. This internal client by nature, externalizes feelings and emotions, and has the ability to transmit them to the people with whom he interacts. For this reason, the present research focuses on analyzing Endomarketing based on Neuro-linguistic Programming present in the self-service hardware stores of the Maracaibo Municipality.

\section{Methodology}

The research focuses on analyzing the behavior of the Endomarketing variable based on Neuro-linguistic programming, by obtaining data from primary sources, which is why it is classified as non-experimental, crosssectional, and descriptive. Not experimental, because studies are carried out without deliberately manipulating the variables and the phenomena are observed in their natural environment to be analyzed [7]; Cross-sectional, 
because it is characterized by describing the variables in their natural environment and at a given time, which have as their object to investigate the values in which one or more variables are manifested [8]; descriptive, by emphasizing in detail the state, characteristics, factors and procedures of the study variables as they occur naturally [9]. The study population was made up of the sales consultants (internal customer) of the self-service hardware stores located in Maracaibo Municipality, as shown in Table 1.

TABLE I. Study population

\begin{tabular}{|c|c|}
\hline Organization & Internal customers \\
\hline Ferretería EPA 11 (circv. nro.1) & 125 \\
\hline Ferretería EPA 14 (C.C. Sambil) & 24 \\
\hline Ferre Total I (Norte) & 47 \\
\hline Ferre Total II (El Milagro) & 55 \\
\hline TOTAL & 251 \\
\hline
\end{tabular}

To select the sample of the finite population, it was calculated according to that indicated in [10], where it is shown that it depends on the amplitude of the finite universe or not, confidence level adopted, estimation error, and standard deviation, as well as of the sample that has been selected. According to the sampling, the formulas vary. For finite universes the author points out Formula 1.

$$
n=\frac{4 . p_{n} q \cdot N}{E^{2}(N-1)+4 \cdot p_{n} q}
$$

Wherein:

$n$ : Sample size

$p$ y $q$ : probabilities of success and failure

$E^{2}: 5 \%$ error

$N$ : Population size

For purposes of calculating the sample, the population consists of a total of 251 sales consultants, the data was substituted in the formula and yielded $n=155$, that is, the instrument will be applied to 155 subjects of the total population.

\section{A. Research instruments}

The technique used in the data collection process was observed by survey. The instrument used in the investigation was a Likert frequency scale questionnaire, which contains five response alternatives with the weights assigned according to the perception according to the case expressed in: totally agree (5), agree (4), neither agree nor disagree (3), disagree (2) and totally disagree (1). An instrument corresponding to the Endomarketing variable based on NLP was developed, consisting of 51 items aimed at internal customers of the hardware stores. The instrument was subjected to the processes of validity and reliability. The validation was in charge of the judgment of seven (7) experts in content and methodological matter in which the work is framed, to proceed with the performance of reliability tests and subsequent application in the selected sample.

Similarly, a pilot test was carried out on a population of 10 internal customers of the self-service hardware stores, in this case the Municipality of San Francisco that are not part of the final sample, to whom the instrument was applied and with the results obtained, the Cronbach coefficient was calculated to determine the reliability (Formula 2).

$$
r_{t t}=\frac{K}{K-1}\left(1-\frac{\sum S_{i}^{2}}{S_{t}^{2}}\right)
$$

Wherein:

K: Number of items that the instrument has

$\mathrm{r}_{\mathrm{tt}}$ : Reliability coefficient

$\mathrm{S}_{\mathrm{i}}^{2}$ : Variance of the scores of each item

$\mathrm{S}_{\mathrm{t}}^{2}$ : Variance of totals

The results of the Cronbach's Alpha coefficient in the pilot test were 0.82 , which is a very high instrument reliability.

\section{B. Data analysis}

The probability corresponding to the study of the dimensions and indicators of the investigation, is categorized using statistical methods such as the mean, fashion, median, standard deviation, variance and the 
coefficient of variation. To interpret the results obtained after the application of these methods, a scale was used (Table 2) taking as a reference the mean, which is the equilibrium point of the analyzed values and the standard deviation that indicates the distance between data.

TABLE II. Scale for the interpretation of the Endomarketing variable based on NLP

\begin{tabular}{|l|l|l|l|l|l|l|}
\hline & & & \multicolumn{4}{|c|}{ Dimensions } \\
\hline & & & $\begin{array}{l}\text { General } \\
\text { average }\end{array}$ & $\begin{array}{l}\text { Endomarketing } \\
\text { factors }\end{array}$ & $\begin{array}{l}\text { NLP } \\
\text { metamodels }\end{array}$ & $\begin{array}{l}\text { Sensory perception } \\
\text { systems }\end{array}$ \\
\hline Rank & Indicator & Interval & Category & Category & Category & Category \\
\hline 5 & Totally agree & $4.21-5.00$ & Very adequate & High influence & $\begin{array}{l}\text { Very suitable } \\
\text { use }\end{array}$ & High applicability \\
\hline 4 & Agree & $3.41-4.20$ & Adequate & Influence & Suitable use & Applicable \\
\hline 3 & $\begin{array}{l}\text { Neither agree } \\
\text { nor disagree }\end{array}$ & $2.61-3.40$ & Neutral & Neutral & Neutral & Neutral \\
\hline 2 & Disagree & $1.81-2.60$ & Inadequate & Low influence & Inadequate use & Inapplicable \\
\hline 1 & $\begin{array}{l}\text { Totally } \\
\text { disagree }\end{array}$ & $1.00-1.80$ & $\begin{array}{l}\text { Very } \\
\text { inadequate }\end{array}$ & $\begin{array}{l}\text { Does not } \\
\text { influence }\end{array}$ & $\begin{array}{l}\text { Very } \\
\text { inadequate use }\end{array}$ & Very inapplicable \\
\hline
\end{tabular}

In Table 2, the interval for the categories of each dimension of the variable is observed, as well as the category of the general average.

\section{III.RESULTS}

Table 3 presents the results obtained from the statistical analysis of the dimensions and sub-dimensions corresponding to the variable Endomarketing based on NLP.

TABLE III. Variable: Endomarketing based on NLP

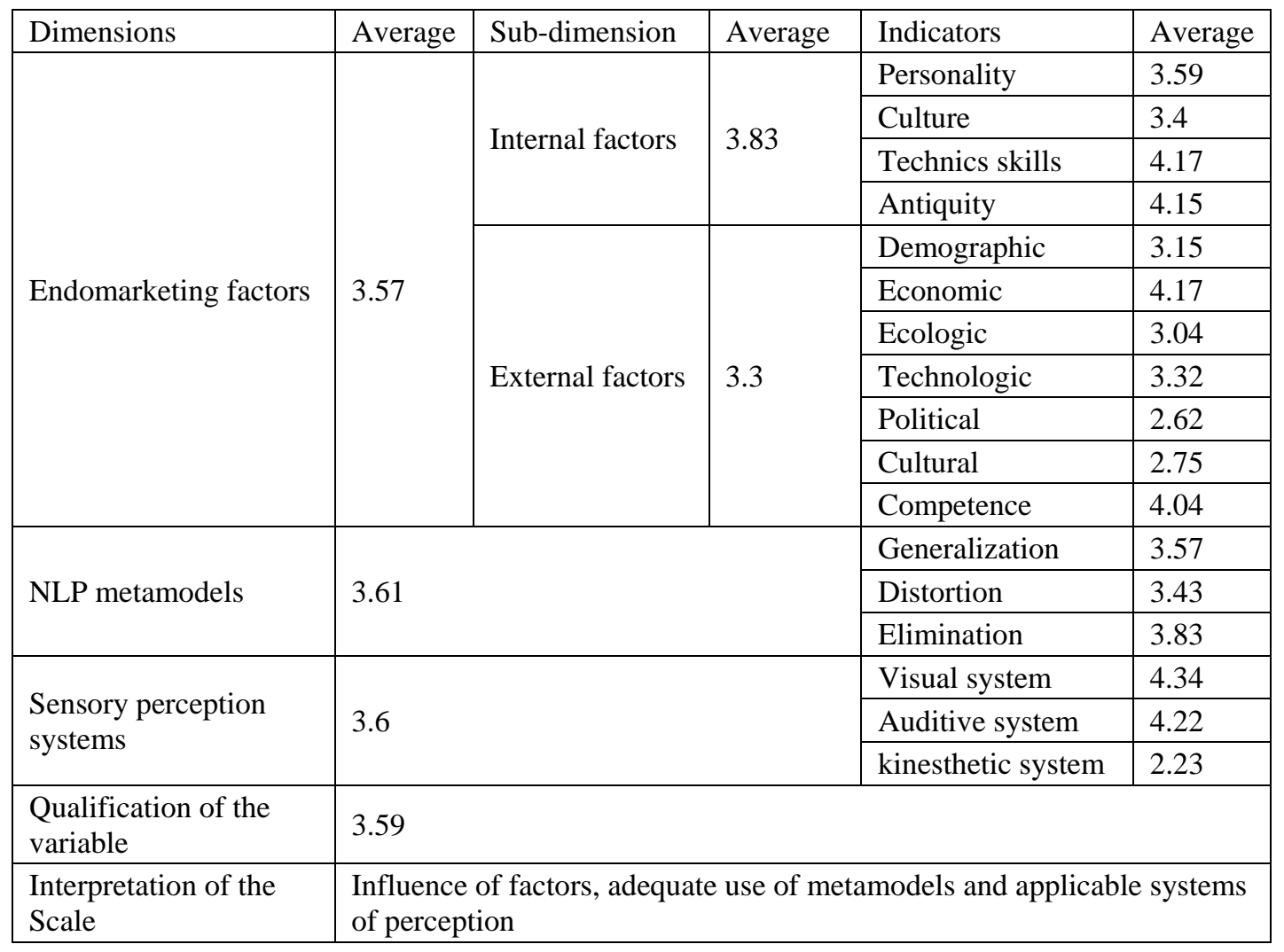

From the results obtained it is observed that the Endomarketing variable based on NLP is placed in the category of adequate for an average of 3.59 and a standard deviation of 1.01 for a moderate dispersion of the answers obtained, as indicated by the scale for the interpretation of results. The above is a consequence of an adequate level in the dimensions of Endomarketing factors, NLP metamodels and sensory perception systems. However, the results of the study show that for sensory perception systems, there is no complete equilibrium and there is no good control regarding external factors. 


\section{A. Dimension: Endomarketing factors}

The results obtained for the Endomarketing factors dimension are shown in Table 4, which indicates that the average was 3.57, placing it in an influential category, with a standard deviation of 1.08 , which corresponds to the moderate category.

TABLE IV. Dimension: Endomarketing factors

\begin{tabular}{|c|c|c|c|}
\hline Dimension & Sub-dimension & Average & $\begin{array}{c}\text { Interpretation according to the } \\
\text { average scale }\end{array}$ \\
\hline Endomarketing Factors & Internal factors & 3,83 & Influence \\
\cline { 2 - 5 } & External factors & 3,3 & Neutral \\
\hline $\begin{array}{c}\text { Qualification of the } \\
\text { dimension }\end{array}$ & \multicolumn{3}{|c|}{3,57} \\
\hline $\begin{array}{c}\text { Interpretation of the } \\
\text { Scale }\end{array}$ & \multicolumn{3}{|c|}{ Influence } \\
\hline
\end{tabular}

As for the value of 3.57 obtained for the average of the dimension, it reflects an influence of the Endomarketing factors in the organizations. This dimension is divided into two sub dimensions, internal factors and external factors. Next, Table 5 shows the results of the internal factors sub-dimension, in which the average is 3.83 , ranking in the influential category according to the scale.

TABLE V. Sub-dimension: Internal factors

\begin{tabular}{|c|c|c|c|}
\hline Sub-dimension & Indicator & Average & $\begin{array}{c}\text { Interpretation according to } \\
\text { the average scale }\end{array}$ \\
\hline \multirow{3}{*}{ Internal factors } & Personality & 3.59 & Suitable \\
\cline { 2 - 4 } & Culture & 3.4 & Suitable \\
\cline { 2 - 4 } & Technical skills & 4.17 & Suitable \\
\cline { 2 - 4 } & Antiquity & 4.15 & Suitable \\
\hline $\begin{array}{c}\text { Qualification of the } \\
\text { dimension }\end{array}$ & \multicolumn{3}{|c|}{3.83} \\
\hline $\begin{array}{c}\text { Interpretation of the } \\
\text { Scale }\end{array}$ & \multicolumn{3}{|c|}{ Influence } \\
\hline
\end{tabular}

The indicators evaluated: personality, culture, technical skills and seniority; they resulted in an influence, which reflects that for the personality indicator the mood of the sales consultant, his attitude and personality, intervene during the interaction with the client, this statement is made based on the results of the average, which was 3.59. This influence is considered negative for the quality of service because the counselor involves their emotions in the process, the attention is subjective and this forces organizations to keep their employees motivated. Regarding the culture indicator; the learned customs, beliefs and values of the internal clients, influence their behavior when interacting with the client, a conclusion which is reached thanks to the value of the average for this item which is 3.4 located in the category of influence. The influence of this indicator is also considered negative because if the sales consultant does not have values, customs and beliefs accepted by the company, the service offered would be considered inappropriate. Therefore, organizations must have special control over this indicator.

In reference to technical skills, the average of this indicator was 4.17 located according to the scale in the category of high influence, which indicates that internal customers apply their expertise to offer customer service and their technical knowledge allow advise correctly. For the seniority indicator, the average was 4.15, which, according to the scale is influential and indicates that the years of service of the internal clients, allows them to perform with greater security in the organization, the time in the hardware store gives commitment to the company and all this allows to offer a quality service.

With the results obtained, it can be inferred that the internal factors are immersed in the organizations and refer to the way of acting of each sales consultant emphasizing that their personality, culture, technical skills and seniority influence when offering customer service because the average of 3.83 for this sub-dimension indicates it according to the established scale. Likewise, more attention should be paid to the personality and culture indicators, since their influence during the rendering of customer service could turn negative according to the point of view evaluated in the investigation. It is important that the hardware stores take more control over the promotion they do with their employees to keep them motivated, because controlling these factors will ensure that the quality of service is objective. 
This situation is consistent with the results obtained by established by [11], where it was found that internal factors have an impact that affects the choice of standardization and adaptation of a company's marketing program. They also state that internal factors shape the behavior of a person in their work and that some of these may be the ability to learn, motivation, perception, attitudes, personality and values. According to what is referred to by [12], the internal factors are within the organization, therefore they can be minimized and even eradicated. This definition indicates that the internal factors, technical skills and seniority are currently controlled because they influence positively, but the factor personality and quality of service, according to the evaluated point of view, negatively influence the quality of service, so which organizations could establish strategies to minimize the effects of them.

As for the sub-dimension External factors, the average for the same was 3.30 which places it in a neutral category. The results for this sub-dimension are expressed in Table 4, where the average is indicated for each indicator and the interpretation of each one.

TABLE VI. Sub-dimension External factors

\begin{tabular}{|c|c|c|c|}
\hline Sub-dimension & Indicator & Average & $\begin{array}{c}\text { Interpretation according to } \\
\text { the average scale }\end{array}$ \\
\hline \multirow{4}{*}{ External factors } & Demographic & 3,15 & Neutral \\
\cline { 2 - 4 } & Economic & 4,17 & Influence \\
\cline { 2 - 4 } & Ecologic & 3,04 & Neutral \\
\cline { 2 - 4 } & Technologic & 3,32 & Neutral \\
\cline { 2 - 4 } & Political & 2,62 & Neutral \\
\cline { 2 - 4 } & Cultural & 2,75 & Neutral \\
\cline { 2 - 4 } & Competence & 4,04 & Influence \\
\hline $\begin{array}{c}\text { Qualification of the } \\
\text { dimension }\end{array}$ & \multicolumn{3}{|c}{3,30} \\
\hline $\begin{array}{c}\text { Interpretation of the } \\
\text { Scale }\end{array}$ & \multicolumn{3}{|c}{ Neutral } \\
\hline
\end{tabular}

For the Demographic indicator, the average was 3.15, which corresponds to the neutral category, which indicates that internal customers may or may not take into account the age of the clients, gender and physical characteristics, when rendering their services. In general, these characteristics are indifferent to them. Regarding the economic indicator and competition, the averages corresponding to each one were 4.17 and 4.04 placing them in the influence category. It is evident with this result that internal clients agree that the current economic environment and the purchasing power of the clients, condition the purchase margin and that the competition between the self-service hardware stores that the advisers know is evident.

With respect to the ecological, technological, political and cultural indicators, they are grouped in the neutral category with averages of 3.04, 3.32, 2.62 and 2.75 respectively. Regarding the ecological indicator, it is evidenced according to the opinion of the internal clients evaluated that the client is indifferent if any product endangers or not their health and the environment, and not in all situations, the advisors indicate when this is the case. When talking about the technological indicator, it was found that internal clients demonstrate a neutral tendency when adapting to the technological changes or benefits offered by organizations. The results referring to the political indicator indicate that according to the point of view of the internal clients, the clients think that the legal and governmental and municipal regulations have a neutral incidence with respect to the provision of the customer service in the self-service hardware stores. Regarding the culture indicator, the perception of the advisors is neutral when referring to the beliefs and values of the clients that interfere when choosing a product and making the purchasing decision.

The external factors that affect the customer service in the self-service hardware stores can be controlled by the organizations, establishing strategies to combat them, however, according to the results obtained, it is evident that the incidence is neutral, which is why they are not completely controlled or combated. This situation contradicts what is expressed by [13], who indicates that external factors are given by the environment and it is difficult to eliminate its effect, in any case they can be combated. This forces companies to be adaptable and flexible to deal with competitors and customers to be innovative and entrepreneurial.

\section{B. Dimension: NLP metamodels}

For this dimension, an average of 3.61 was obtained, which reflects an adequate use of NLP metamodels by internal clients. Table 5 details the average of this dimension, as well as its indicators that are generalization, distortion and elimination; with its statistical results and the corresponding interpretation of them. 
TABLE VII. Dimension: NLP metamodels

\begin{tabular}{|c|c|c|c|}
\hline Dimension & Indicator & Average & $\begin{array}{c}\text { Interpretation according to } \\
\text { the average scale }\end{array}$ \\
\hline \multirow{3}{*}{ NLP Metamodels } & Generalization & 3,57 & Suitable use \\
\cline { 2 - 4 } & Distortion & 3,43 & Suitable use \\
\cline { 2 - 4 } & Elimination & 3,83 & Suitable use \\
\hline $\begin{array}{c}\text { Qualification of the } \\
\text { dimension }\end{array}$ & \multicolumn{3}{|c|}{3,61} \\
\hline $\begin{array}{c}\text { Interpretation of the } \\
\text { Scale }\end{array}$ & \multicolumn{3}{|c|}{ Suitable use } \\
\hline
\end{tabular}

The NLP metamodels are a tool that self-service hardware stores should implement to improve the interpersonal communication of the sales consultant, which adds aspects favorable to the quality of service offered by them. According to the result obtained for this sub dimension, the use of metamodels of internal customers in the hardware stores is adequate, but this is an episode that occurs without them having the knowledge. The results agree with what authors related to the subject express, such as [14], where it is indicated that when talking about language metamodels in Neuro-linguistic programming, it refers to how language is used. Similarly, metamodels are used by the brain to interpret and reconnect the meaning behind words in an interaction [15]. The results show that in the self-service hardware stores studied, unconsciously a correct use is given to the language. It is important to highlight the possibility of informing internal clients of the meaning of metamodels so that conscious models of language are implemented to help improve the quality of service offered.

Regarding the indicators corresponding to this dimension; generalization resulted in an average of 3.57, which indicates that it is in the category of adequate use. Said result refers that the internal clients react in the same way as in similar past situations when rendering their services to the client, takes into account previous satisfactory experiences and always acts in the same way when presented with situations similar to those already experienced. Regarding the distortion indicator, the average of the indicator was 3.43 located in the appropriate category of use, which indicates that a large part of the internal clients modify the reality of a specific situation during the customer's purchase process, they add important changes to a situation to obtain effective results and alter the information provided by the client when answering your request.

In this regard, in [16] it is indicated that the concept of generalization of suppression and distortion of information during communication was developed as a central principle of the meta-model of NLP, in addition, the distortion is a significant change of reality, it is the process by which the experience of the perceived data is modified. For the elimination indicator, the average was 3.83, which also places it in the category of adequate use. This result gives grounds for inferring that the advisor selects from the information provided by the client, the most important to respond to his request and chooses the one that he must exclude because it is not relevant at the time of responding to requests.

\section{Dimension: Sensory perception systems}

The results of the statistical analysis of the indicators corresponding to the sensory perception systems dimension are reflected in Table 6. In this research work, the assumed indicators reflect the predominant representative system that the sales consultant has and that this information can be used to offer effective customer service.

TABLE VIII. Dimension: Sensory perception systems

\begin{tabular}{|c|c|c|c|}
\hline Dimension & Indicator & Average & $\begin{array}{c}\text { Interpretation according to the } \\
\text { average scale }\end{array}$ \\
\hline \multirow{2}{*}{$\begin{array}{c}\text { Sensory perception } \\
\text { systems }\end{array}$} & Visual & 4.34 & High applicability \\
\cline { 2 - 4 } & Auditive & 4.22 & High applicability \\
\cline { 2 - 4 } $\begin{array}{c}\text { Qualification of the } \\
\text { dimension }\end{array}$ & 2.23 & Very inapplicable \\
\hline $\begin{array}{c}\text { Interpretation of the } \\
\text { Scale }\end{array}$ & \multicolumn{2}{|c|}{3.60} \\
\hline
\end{tabular}


As can be seen in Table 6, the dimension "perception systems" obtained a value for the average of 3.60, placing it in an applicable category. At this point it should be noted that there is no complete balance in the use of perceptual systems, the predominant ones being visual and auditory according to the results of their means. In this regard, [17] they affirm that each person has a dominant sensory representation system, but almost never is aware of their own sensory references. What allows to express that, the individual observes each person of the organization, understands that the requirements depend on their own reference frame. This definition is adjusted to the results obtained and previously exposed where it is indicated that the internal clients have a predominant perceptual system, however, according to the results obtained by each indicator, the predominant ones are a combination between the visual and the auditory, leaving the kinesthetic as the representative system less used and, the advisors are not aware of their own sensory references and the utility of them to offer excellent customer service.

As for the indicator "visual", the average corresponding to it is 4.34 placing it in the category of high applicability. It can be inferred, thanks to this result, that this representative system predominates among internal clients. Their predominant way of perceiving everything they have around them is visually, they store information in their mind through images and they have a visual connection with the client during the communication process. This is further demonstrated by the results obtained in item 43 which refers to the predominant way of perceiving everything that the advisor has visually around him. This result is expressed in Table 9 below, where the evaluation made to the visual indicator is detailed.

TABLE IX. Indicator "Visual”

\begin{tabular}{|c|c|c|c|c|c|c|c|c|}
\hline \multirow{3}{*}{$\begin{array}{l}\text { Informants } \\
\text { Response alternatives }\end{array}$} & \multicolumn{8}{|c|}{$\begin{array}{l}\text { Internal customers of the self-service hardware stores of the Maracaibo } \\
\text { Municipality }\end{array}$} \\
\hline & \multicolumn{2}{|c|}{ ITEMS 43} & \multicolumn{2}{|c|}{ ITEMS 44} & \multicolumn{2}{|c|}{ ITEMS 45} & \multicolumn{2}{|c|}{ Average of the indicator } \\
\hline & $\mathrm{AF}$ & $\%$ & $\mathrm{AF}$ & $\%$ & $\mathrm{AF}$ & $\%$ & $\mathrm{AF}$ & $\%$ \\
\hline Totally agree & 55 & 35.5 & 73 & 47.1 & 67 & 43.2 & 65.00 & 41.94 \\
\hline Agree & 77 & 49.7 & 74 & 47.7 & 80 & 51.6 & 77.00 & 49.68 \\
\hline Neither agree nor disagree & 23 & 14.8 & 8 & 5.2 & 8 & 5.2 & 13.00 & 8.39 \\
\hline In disagreement & 0 & 0 & 0 & 0 & 0 & 0 & 0.00 & 0.00 \\
\hline Totally disagree & 0 & 0 & 0 & 0 & 0 & 0 & 0.00 & 0.00 \\
\hline Totals & 155 & 100 & 155 & 100 & 155 & 100 & 155 & 100.00 \\
\hline Half & \multicolumn{2}{|l|}{4.21} & \multicolumn{2}{|c|}{4.42} & \multicolumn{2}{|c|}{4.38} & \multicolumn{2}{|l|}{4.34} \\
\hline Standard deviation & .681 & & .591 & & .584 & & 0.62 & \\
\hline $\begin{array}{l}\text { Interpretation according to } \\
\text { the average scale }\end{array}$ & \multicolumn{8}{|c|}{ High applicability } \\
\hline $\begin{array}{l}\text { Interpretation according to } \\
\text { the standard deviation scale }\end{array}$ & \multicolumn{8}{|c|}{ Low dispersion } \\
\hline
\end{tabular}

According to these results, $49.7 \%$ of the internal clients surveyed agreed that their dominant representative system is visual and $35.5 \%$ totally agreed. These values are obtained thanks to the statistical results for the corresponding absolute frequency for item 43 , which was 55 for the totally agreed alternative and 77 for the alternative agreement, which shows the level of acceptance and agreement that the The predominant way of perceiving everything that you have around you is visually. For the auditory indicator, an average of 4.22 was obtained, placing it in the same way as the visual one, in the category of very suitable. When interpreting this result, it is evident that the internal clients also have the auditory system as the dominant system.

Evaluating item 46 that indicates that the predominant way of perceiving everything around you is through hearing, interesting results are detailed that can be observed in Table 10. 
TABLE X. Indicator “Auditive”

\begin{tabular}{|l|l|l|l|l|l|l|l|l|}
\hline \multirow{2}{*}{ Informants } & \multicolumn{7}{l}{ Internal customers of the self-service hardware stores of the Maracaibo } \\
Municipality
\end{tabular}

According to the results obtained in item 46, of 155 evaluated sales consultants, 24 fully agree, 50 agree and 73 neither agree nor disagree that their dominant representative system is auditory. This result is derived from the value of the absolute frequency for each response alternative of item 46. For the kinesthetic indicator, the result of the average is 2.23 according to what is expressed in Table 8 above and the interpretation of this value places it in the category of inadequate. With this it is evident that for the internal customers of the self-service hardware stores, the representative kinesthetic system is not predominant. Next, the results of the kinesthetic indicator are detailed in Table 9, where item 49 is detailed, which indicates that the predominant way of perceiving everything around it is through touch.

TABLE XI. Indicator "Kinesthetic"

\begin{tabular}{|c|c|c|c|c|c|c|c|c|}
\hline Informants & \multicolumn{8}{|c|}{$\begin{array}{l}\text { Internal customers of the self-service hardware stores of the Maracaibo } \\
\text { Municipality }\end{array}$} \\
\hline \multirow[t]{2}{*}{ Response alternatives } & \multicolumn{2}{|c|}{ ITEMS 46} & \multicolumn{2}{|c|}{ ITEMS 47} & \multicolumn{2}{|c|}{ ITEMS 48} & \multicolumn{2}{|c|}{ Average of the indicator } \\
\hline & $\mathrm{AF}$ & $\%$ & $\mathrm{AF}$ & $\%$ & $\mathrm{AF}$ & $\%$ & $\mathrm{AF}$ & $\%$ \\
\hline Totally agree & 24 & 15.5 & 14 & 9.0 & 14 & 9.0 & 17.33 & 11.18 \\
\hline Agree & 10 & 6.5 & 0 & 0 & 0 & .0 & 3.33 & 2.15 \\
\hline Neither agree nor disagree & 20 & 12.9 & 46 & 29.7 & 33 & 21.3 & 33.00 & 21.29 \\
\hline In disagreement & 65 & 41.9 & 44 & 28.4 & 28 & 18.1 & 45.67 & 29.46 \\
\hline Totally disagree & 36 & 23.2 & 51 & 32.9 & 80 & 51.6 & 55.67 & 35.91 \\
\hline Totals & 155 & 100 & 155 & 100 & 155 & 100 & 155 & 100.00 \\
\hline Half & \multicolumn{2}{|l|}{2.49} & \multicolumn{2}{|l|}{2.24} & \multicolumn{2}{|c|}{1.97} & \multicolumn{2}{|l|}{2.23} \\
\hline Standard deviation & \multicolumn{2}{|c|}{1.336} & \multicolumn{2}{|c|}{1.179} & \multicolumn{2}{|c|}{1.245} & \multicolumn{2}{|l|}{1.25} \\
\hline $\begin{array}{l}\text { Interpretation according to } \\
\text { the average scale }\end{array}$ & \multicolumn{8}{|c|}{ Applicable } \\
\hline $\begin{array}{l}\text { Interpretation according to } \\
\text { the standard deviation scale }\end{array}$ & \multicolumn{8}{|c|}{ High dispersion } \\
\hline
\end{tabular}

Of 155 evaluated sales consultants, only 24 indicated that they fully agree and 10 that they agree that their dominant representative system is kinesthetic. 20 advisors are neither in agreement nor disagreement, 65 in disagreement and 36 totally in disagreement. It is important to note that for this indicator, the standard deviation is in the high dispersion category, which means that there is a great difference in response types. Table 12 shows, according to the results obtained in the visual, auditory and kinesthetic indicators, the dominant representative system in the self-service hardware stores of the Maracaibo Municipality. 
TABLE XII. Predominant evaluation for perception systems

\begin{tabular}{|c|c|c|c|c|c|}
\hline \multirow[b]{2}{*}{ Ítem } & \multirow[b]{2}{*}{ Description } & \multicolumn{3}{|c|}{ Evaluation according to the average scale } & \multirow{2}{*}{$\begin{array}{l}\text { Predominant } \\
\text { evaluation }\end{array}$} \\
\hline & & Proper trend & Neutral trend & \begin{tabular}{|l|} 
Inadequate \\
trend
\end{tabular} & \\
\hline 43 & $\begin{array}{l}\text { The predominant way of } \\
\text { perceiving everything you } \\
\text { have around you is visually }\end{array}$ & $\begin{array}{l}132 \\
\text { consultants/85, } \\
2 \%\end{array}$ & $14,80 \%$ & $0 \%$ & $\begin{array}{l}\text { Applicable } \\
\text { trend }\end{array}$ \\
\hline 46 & $\begin{array}{l}\text { The predominant way of } \\
\text { perceiving everything you } \\
\text { have around you is through } \\
\text { hearing }\end{array}$ & $\begin{array}{l}74 \\
\text { consultants/47, } \\
5 \%\end{array}$ & $\begin{array}{l}73 \\
\text { consultants/4 } \\
7,1 \%\end{array}$ & $5,20 \%$ & $\begin{array}{l}\text { Applicable - } \\
\text { Neutral trend }\end{array}$ \\
\hline 49 & $\begin{array}{l}\text { The predominant way of } \\
\text { perceiving everything you } \\
\text { have around you is through } \\
\text { touch }\end{array}$ & $22 \%$ & $12,90 \%$ & $\begin{array}{l}101 \\
\text { consultants/ } \\
65,1 \%\end{array}$ & $\begin{array}{l}\text { Inapplicable } \\
\text { trend }\end{array}$ \\
\hline
\end{tabular}

According to Table 10, 132 consultants agree that their representative system is the visual, in turn, of these 155 advisors, 74 agree that their representative system is also auditory and 73 advisors they do not agree or disagree that it is. 102 advisers disagree that their representative system is the kinesthetic, so it can be inferred that the predominant systems in the internal clients are the visual and the auditory. This result indicates that there is a tendency towards visual and auditory systems, with kinesthetic being not so predominant.

\section{IV.CONCLUSION}

The results obtained in the research conducted to analyze the NLP-based Endomarketing, allow the following conclusions to be drawn:

When describing the Endomarketing factors based on Neuro-linguistic programming of the study population, it was concluded that according to the perception of the internal clients, the internal factors, technical skills and seniority, are controlled and have a positive influence on the process, but the factors internal personality and culture, influence negatively according to the context evaluated. Regarding the external factors which are demographic, economic, ecological, technological, political, cultural, and competition; over which the organizations have no power, are not fully controlled so it can be concluded that these factors negatively influence the provision of customer service. Likewise, by identifying the metamodels of Neuro-linguistic programming, the adequate use of metamodels, generalization, distortion and elimination, which are correctly used in the organizations under study, despite the fact that internal clients have no knowledge of the existence, was evidenced and utility of them.

When identifying the NLP perception systems, it was found that most of the internal clients have a combination of the visual and auditory system as a representative system, with kinesthetic being the least applied in the evaluated population. Finally, it is generally concluded that in the organizations under study, internal marketing is not implemented and the tools of NLP are not taken into account, which can be of great help in improving the quality of service and even, to sell the company to its own employees.

\section{REFERENCES}

[1] M. Karunaratne, "Neuro-linguistic programming and application in treatment of phobias," Complementary therapies in clinical practice, vol. 16, no. 4, pp. 203-207, 2010.

[2] H. Skinner, and P. Stephens, "Speaking the same language: the relevance of neuro-linguistic programming to effective marketing communications,” Journal of Marketing Communications, vol. 9, no. 3, pp. 177-192, 2003.

[3] L. Joey, and R. Yazdanifard, "Can Neuro-Linguistic Programming (NLP) be used as contemporary and effective skill for an exceptional manager in an organization?," International Journal of Management, Accounting and Economics, vol. 2, no. 5, pp. 456465, 2015.

[4] H. J. Hejase, and F. Hashem, "Neuro-linguistic programming and leadership: an exploratory study on lebanese management," European Journal of Business and Social Sciences, vol. 4, no. 9, pp. 121-155, 2015.

[5] A. Singh, and A. Abraham, "Neuro linguistic programming: A key to business excellence," Total Quality Management \& Business Excellence, vol. 19, no. 1-2, pp. 141-149, 2008.

[6] W. R. George, "Internal marketing for retailers: The junior executive employee," In Proceedings of the 1984 Academy of Marketing Science (AMS) Annual Conference, (pp. 322-325). Springer, Cham, 2015.

[7] R. Kumar, Research methodology, a step by step guide for beginners, 3rd edition. SAGE, 2003.

[8] E. Babbie, The basics of social research, 5th edition. Belmont, CA, USA: Wadsworth Cengage Learning, 2011.

[9] K. S. Bordens, and B. B. Abbott, Research Design and Methods: A Process Approach. New York: McGraw-Hill Education, 2018.

[10] N. Chávez, Introducción a la investigación educativa. Maracaibo: Venezuela Grafica González, 2007.

[11] M. Gustafsson, and M. Tegnhammar, "International Marketing Strategy: A qualitative study of how a company's internal factors influence choice of standardization versus adaptation,” Dissertation, 2015. 
[12] F. L. Eichorn, "Internal customer relationship management (IntCRM) a framework for achieving customer relationship management from the inside out,” Problems and Perspectives in Management, vol. 1, no. 1, pp. 154-177, 2017.

[13] M. S. Qureshi, N. Aziz, N. and S. A. Mian, "How marketing capabilities shape entrepreneurial firm's performance? Evidence from new technology based firms in turkey,” Journal of Global Entrepreneurship Research, vol. 7, pp. 1-15, 2017.

[14] E. Olsson, and J. Rexmyr, "Customer's perception of Neuro-Linguistic Programming (NLP) techniques in sales communication," Dissetation, 2017.

[15] N. A. N. B. Zulkifli, "Neuro-linguistic Programming (NLP) and Transformational Leadership: A Conceptual Model for Malaysian Women Leader and Representative,” Journal of Media and Information Warfare, vol. 7, pp. 105-160, 2015.

[16] M. I. Johnson, and M. Hudson, "Generalizing, deleting and distorting information about the experience and communication of chronic pain,” Pain Management, vol. 6, no. 5, pp. 411-414, 2016.

[17] A. Murata, W. Wen and H. Asama, "The body and objects represented in the ventral stream of the parieto-premotor network," Neuroscience research, vol. 104, pp. 4-15, 2016.

\section{AUTHOR PROFILE}

Ligia Bermudez works as Industrial Engineer at Tus Pisos Enterprise (Venezuela). Mrs. Bermudez completed her magister from Rafaél Bellozo Chacin University (Venezuela). Mrs. Bermudez completed her undergraduate in Industrial Engineering at the University of Zulia.

Raul J. Martelo works as full-time professor at the University of Cartagena (Colombia). Mr. Martelo completed his magister from Industrial University of Santander (Colombia). Mr. Martelo completed his undergraduate in Systems Engineering at the Industrial University of Santander.

Piedad M. Montero works as full-time professor at the University of Cartagena (Colombia). Mrs. Montero completed her doctorate from Rafael Belloso Chacin University (Venezuela). Mrs. Montero completed her undergraduate in Food Engineering at the University of Cartagena. 